\title{
Typological and Diachronic Motivations for Syntax and Semantics of Chinese Resultative Construction
}

\author{
Canzhong Jiang \\ College of International Studies, Southwest University, Chongqing, China
}

\begin{abstract}
Motivations for syntax and semantics of Chinese Resultative Construction have been primarily attributed to thematic operations, syntactic movements or argument raising within its components by previous researches. However, such an attribution has resulted in not inconsiderable theoretical and practical issues and controversies, e.g., over generation, existence of quite a few exceptions, unlicensed violations of theoretical rules and principles. This paper re-examined motivations for syntax and semantics of Chinese Resultative Construction from typological and diachronic perspectives within the framework of Construction Grammar. It is argued that syntax and semantics of Chinese Resultative Construction are typologically motivated by Causative Constructions in the sense that its syntactic and semantic properties are inherited from different kinds Causative Constructions while they are diachronically motivated in the senses that they are historically inherited from Serial Verb Construction [V V] due to semantic shift and disyllabification. This paper has provided totally different explanations for syntax and semantics of Chinese Resultative Construction by focusing on their gestalt properties, in stark contrast to previous emphasis on bottom-up motivations from components of Chinese Resultative Construction, which will prove a breakthrough for further research on syntax-semantics interface of Chinese Resultative Construction.
\end{abstract}

Index Terms-Chinese resultative construction, construction grammar, motivation, linguistic typology, diachrony

\section{INTRODUCTION}

Chinese Resultative Construction (represented as [V R], henceforward CRC) is a highly debated topic in Chinese Linguistics. It encodes causative meaning and has long been thought of as a Chinese-specific construction which manifests the syntactic flexibility and structural conciseness for rich meaning. The main reason why CRC was thought to Chinese-specific is that two separate predicates are juxtaposed to convey causing event and result event respective but unlike what Comrie (1989) has called Analytical Causative Construction, CRC behaves like a single predicate, and is even endowed with a high productivity. In other words, it is neither Analytical Causative Construction, nor Morphological Causative Construction, nor Lexical Causative Construction in Comrie's (1989) sense.

Previous researches on CRC have focused primarily on the structural uniqueness of CRC, and paid too much attention to how its syntax and semantics can be derived from its components. Even though tremendous achievements have been gained on this topic, there still remains not inconsiderable issues and controversies, especially in terms of motivations for syntax and semantics of CRC. Previous researches have mainly been confided to verb-centered and reductionism-oriented views and attempted to explore motivations for syntax and semantics of CRC from its components by thematic operation, syntactic movement or argument raising. However, this practice has neglected the holistic or gestalt properties of CRC, which results in issues and controversies concerning over generation, existence of quite a few exceptions, unlicensed violations of theoretical rules and principles, to name just a few. Therefore, it is in urgent need to re-scrutinize motivations for syntax and semantics of CRC from new perspectives. This paper attempts to investigate this issue from typological and diachronic perspectives within the framework of Construction Grammar.

\section{Previous Research on Motivations For SyntaX And Semantics of CRC}

Syntactic and semantic motivations for CRC have been explored by various strands of linguistic theories but unfortunately CRC has also posed some threats to those theories. In this part, we will review how it has been explained by Generative Linguists, Valency Grammarians, and Cognitive Linguists as well.

Researches on syntactic and semantic motivations for CRC from the Generative Linguistic perspective divide into two groups, with one group arguing that CRC is derived from its components through lexical rules, while the other claiming that it is the derivation of its components through syntactic rules, or more specifically syntactic movements. $\mathrm{Li}$ $(1990,1993,1995,1999)$ is the representative of the lexical group. He maintained that CRC is a kind of compound verbs with $\mathrm{V}$ being the head, and it projects to the syntax directly. Its thematic structure is derived from the theta roles of its component verbs through thematic operations including Theta Identification, Structured Theta-grid, Head-feature Percolation (Li, 1990, 1993). This, however, only explains such prototypical instances as (1a), but fails to account for 
those of (1b). In this case, Li (1995) distinguished two hierarchies, the thematic hierarchy and the causative hierarchy. The former is devised for prototypical instances of CRC while the latter for non-prototypical ones like (1b). However, the existence of this thematic hierarchy has been extensively criticized for its being ad hoc, and specially set for CRC like (1b) (see Shi, 1998; Her, 2007; Huang, 2008; Xuan, 2011).
(1) a. Ta [da-po]
le boli
chuang.
3sg [hit-broken] PERF glass window

Lit.: He hit and caused the window to break.

'He broke the window'

$\begin{array}{lllll}\text { b. Jihuang } & \text { [e-si] } & \text { le } & \text { henduo } & \text { ren } \\ \text { starvation } & \text { [starve-dead] } & \text { PERF } & \text { many } & \text { people }\end{array}$

Lit:: The starvation starved many people and caused them to die

'The starvation starved many people to death'

Sybesma (1999) is the representative of the syntactic group and he copes with CRC quite differently from the lexical group does. According to Sybesma, CRC is a kind of syntactic structure and is the result of the direct syntactic projection of its composing verbs through syntactic movement. However, syntactic movement rules also come across exceptions when confronted with (1b). In this case, a light verb CAUSE without phonetic realization is introduced during syntactic movement. However, this approach also suffered the same criticism as the lexical group did.

Valency Grammarians adopts a quite similar view to the lexical group in Generative Linguistic approach, but they emphasize on the valency of composing verbs in CRC and attempt to illustrate the syntax and semantics of CRC through argument raising. This approach is represented by works of Wang (1995), Guo (1995, 2002), Yuan (2001) and Shi (2008). According to them, arguments of $\mathrm{V}$ and $\mathrm{R}$ are raised, in line with a set of prescribed rules, as semantic roles of CRC. However, when this explanation is faced with instances like (1b), the causer of CRC has to be conceived as introduced either externally or by a causative hierarchy which remains to be controversial.

Main stream researches on motivations for syntax and semantics of CRC are exclusively conducted from Generative Linguistic and Valency Grammar approaches. There are also few studies on the topic employing a Cognitive Linguistic approach for example Shen (2004), Song (2007), Zhao (2008a, 2008b, 2009a, 2009b) and Xiong \& Wei (2014a, 2014b), etc. Shen (2004) and Song (2007) resort to Talmy's Force Dynamic theory and claim that CRC are metaphorical extensions of Caused Motion Construction. They have been concerned with the conceptual structure or event structure, i.e., the semantics of CRC. According to them, semantics of CRC is motivated by Caused Motion Construction through metaphor. However, the metaphorical link between Resultative Construction and Caused Motion Construction is still controversial (Boas, 2003; Wang, 2009, 2011; Dong, 2014). Zhao (2008a, 2008b, 2009a, 2009b) and Xiong \& Wei (2014a, 2014b) adopt a Construction Grammar approach. These studies are carried out on the basis of Goldberg's research of English Resultative Construction (Goldberg, 1995). Consequently, they regard CRC as an Argument Structure Construction just like English Resultative Construction, and try to explicate syntax and semantics of CRC in terms of the fusion of verbs composing CRC with Argument Structure Construction. However, in the process of fusion, the Semantic Coherence Principle is quite liable to be violated, thus leading to the abuse of coercion.

In summary, most of previous researches have prioritized the components of CRC and seek to explain the motivations for CRC's syntax and semantics from the syntax and semantics of its composing verbs. Such a verb-centered and reductionism-oriented perspective has suffered from various theoretical and practical problems, such as prescription of ad hoc rules, violations of Theta Criteria, Uniformity of Theta Assignment Hypothesis (UTAH), or Semantic Coherence Principle, and over generation or insufficient explanation for all kinds of CRC. That is also the reason why we advocate new explanations for motivations for syntax and semantics of CRC from both linguistic typological and diachronic perspectives within the framework of Construction Grammar, which will put gestalt properties of syntax and semantics of CRC in the first place instead components of CRC.

\section{Typological Motivations For Syntax AND SEMANTICS OF CRC}

The reason why previous exploration of motivations for syntax and semantics of CRC suffered from various theoretical and practical problems is that they are restricted to the components of CRC and equate the syntax and semantics with that of the composing verbs, which neglects the holistic or gestalt properties of CRC. This paper adopts a Construction Grammar approach which argues that linguistic knowledge is a structured inventory of constructions, form-meaning pairings, with varying degree of complexity and schematicity (Langacker, 1987; Goldberg, 1995, 2006; Hilpert, 2014). In this sense, CRC is a construction. On this prerequisite, motivations for syntax and semantics of CRC have to be re-examined since as a construction CRC is characterized by idiosyncratic syntax and semantics that are independent of its components. Therefore, the linguistic typological perspective is invoked. We will analyze how syntax and semantics of CRC can be motivated by that of Causative Construction, or more specifically, how gestalt properties of syntax and semantics of CRC can be explained by typological relations between CRC and Causative Construction.

\section{A. Constructionhood of CRC}

According to Goldberg (1995, p.4), "C is a construction iff ${ }_{\text {def }} \mathrm{C}$ is a form-meaning pair $\left\langle\mathrm{F}_{\mathrm{i}}, \mathrm{S}_{\mathrm{i}}\right\rangle$ such that some aspect of $\mathrm{F}_{\mathrm{i}}$ or some aspect of $\mathrm{S}_{\mathrm{i}}$ is not strictly predictable from C's component parts or from other previously established 
constructions". Influenced by Langacker (2005), Goldberg (2006, p.5) re-defined construction as any linguistic pattern "as long as some aspect of its form or function is not strictly predictable from its component parts or from other constructions recognized to exist" and "patterns are stored as constructions even if they are fully predictable as long as they occur with sufficient frequency". The definition is simplified as "learned form-function pairings at varying levels of complexity and abstraction" in Goldberg (2013, p.17). Although interpretations for a construction vary, one thing remains constant, that is, whether a construction is formally/semantically predictable or not, it is an entrenched pattern with holistic or gestalt properties. Based on such an understanding, we claim that CRC is a construction and in particular, it's a Complex Predicate Construction instead of Argument Structure Construction like English Resultative Construction.

First of all, CRC is formally characterized by idiosyncratic features that are independent of its component verbs. The most direct manifestation of this formal idiosyncrasy is that the transitivity of the whole is irrelevant to either $\mathrm{V}$ or $\mathrm{R}$. For example, when $\mathrm{V}$ is intransitive and so is $\mathrm{R}$, CRC can either be transitive or intransitive construction, with the transitive case instantiated by zhan-lei 'stand-tired' in (2a) while intransitive case by nao-xing 'make noises-awake' in (2b). In addition, as Shi (2008) has pointed out, CRC as a whole conveys the function of predication but syntactically behaves differently from simple verbs that constitute it. Semantically, the meaning of CRC, i.e., causative meaning cannot be predicted from its components. In other words, both syntax and semantics of CRC are featured by idiosyncrasies not predictable from its components. Thus, it is a construction. However, what kind of construction is it, Argument Structure Construction like English Resultative Construction, or Complex Predicate Construction?

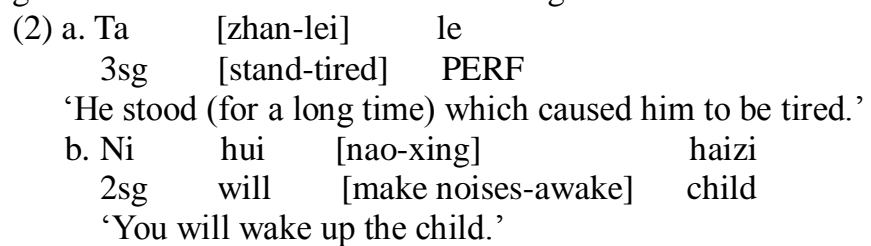

Zhao (2008a, 2008b, 2009a, 2009b) and Xiong \& Wei (2014a, 2014b) have claimed that CRC is an Argument Structure Construction as they referred to researches on English Resultative Construction by Goldberg (1995). However, they have been frustrated by unlicensed violations of the Semantic Coherence Principle and rampant construction coercion, which means they may have misunderstood CRC. We re-analyzed CRC from a typological perspective and argue that it is Complex Predicate Construction (in the narrow sense), instead of Argument Structure Construction like English Resultative Construction.

Complex Predicate Construction is composed by two or more verbs whereby no explicit coordination, subordination or other syntactic dependent relations exist between these composing verbs (Aikhenvald, 2006, p.1). It behaves like but is not equal to simple verbs. For example, it has the same tonic feature as a simple verb and occupies the core syntactic position in a clause as the predicate (Aikhenvald, 2006; Haspelmath, 2016). According to these properties proposed by Aikhenvald (2006), Haspelmath (2016), as well as other typological studies, for Complex Predicate Construction, CRC is exactly a Complex Predicate Construction since CRC is composed of two verb $\mathrm{V}$ and $\mathrm{R}$, and there is no explicit syntactic relations between them, and additionally, [V R] as a whole behave like a single verb.

The constructionhood of CRC means that any analyses of CRC have to take into consideration its gestalt properties and its syntax and semantics cannot be fully motivated by the syntax and semantics of its components.

\section{B. Syntactic Inheritance Relations between CRC and Causative Constructions}

Causativity is a basic semantic category and all languages are equipped with linguistic devices to convey causative meaning (Shibatani, 2002). However, linguistic devices vary cross-linguistically even within a single language. For example, English uses the Argument Structure Construction [Subj V Obj Obl] to encode causative meaning while in Chinese causative meaning is encoded by Complex Predicate Construction [V R]. There are actually two kinds of Resultative Constructions in Chinese, the juxtaposed form [V R] and the detached form [V DE(得) R].

Comrie (1989) distinguished three types of Causative Constructions by formal parameters through linguistic typological studies, that is, Analytical Causative Construction, Morphological Causative Construction, and Lexical Causative Construction. These three Causative Constructions are characterized by distinctive features. Analytical Causative Construction is characterized by employing separate predicates to express the notion of causative and the result (Comrie, 1989, 167). For example, in (3) shi 'cause' is used to express causative meaning while a separate verb renshi 'recognize' is invoked to express the ensuing result. The most prototypical Morphological Causative Constructions are causatives relating a non-causative predicate through morphological devices, such as affixation. For example, in ancient Chinese language, a change of tone is utilized to derive a causative construction from the non-causative equivalent. Such a device leaves its traces even in modern Chinese, as in (4a) and (4b) where y̌n means to drink while yin to make someone drink. In addition, Morphological Causative Construction is prototypically productive. As for Lexical Causative Construction, independent lexical constructions are used to express a causative meaning and its counterpart, for example, the use of die and kill in English.

$\begin{array}{cccccc}\text { (3) jiaoyu } & \text { shi } & \text { ni } & \text { renshi } & \text { le } & \text { zhenli } \\ \text { Education } & \text { cause } & 2 s g & \text { recognize } & \text { PERF } & \text { truth }\end{array}$


'Education caused you to recognize the truth.'

(4) a. yinn shui si yaun

Drink water consider source

'While drinking, don't forget the water's source.'

b. yìn niu huilai...

drink cattle return

Lit.: Return after making the cattle drink.

CRC is usually construed to be neither a prototypical case of Analytical Causative Construction, nor Morphological Causative Construction, nor Lexical Causative Construction. However, seen from the other way around, it inherits properties from all of these Causative Constructions. The property of employing separate verbs to express causing event and result event is inherited from Analytical Causative Construction but different from Analytical Causative Construction, two separate verbs in CRC are juxtaposed. Most of Vs or Rs in CRC behave like affixes (though they are not in essence) and thus CRC is quite productive in modern Chinese. Such a property of productivity is inherited from Morphological Causative Construction. At the same time, CRC is a distinct construction from the non-causative use the lexical constructions V or R. In this sense, it is also syntactically related to Lexical Causative Construction.

In summary, from the linguistic typological perspective, CRC is essentially a hybrid type of Causative Construction which has inherited formal properties of Analytical Causative Construction, Morphological Causative Construction, and Lexical Causative Construction. Therefore, syntax of CRC is motivated by Causative Constructions.

\section{Semantic Inheritance Relations between CRC and Causative Constructions}

On the basis of a tripartite categorization of Causative Constructions, Haiman (1985), Comrie (1989), Dixon (2000, 2012), Fan (2000), Guo \& Ye (2001), etc., investigated the causative meanings expressed by different Causative Constructions. They found that causative meanings vary across those Causative Constructions in the sense that causative meanings expressed by some Causative Constructions are more direct and compact than that of others. In other words, Causative Constructions differ in causative meanings in terms of their directness and compactness to the extent that such directness and compactness is positively related to the formal compactness of those Causative Constructions. According to these researchers, Lexical Causative Construction is most compact in form, with the formal compactness decreasing from Morphological Causative Construction to Analytical Causative Construction. Consequently, directness and compactness of causative meaning decrease along with the compactness of formal compactness of those Causative Constructions, which can be represented as a hierarchy in Figure 1.

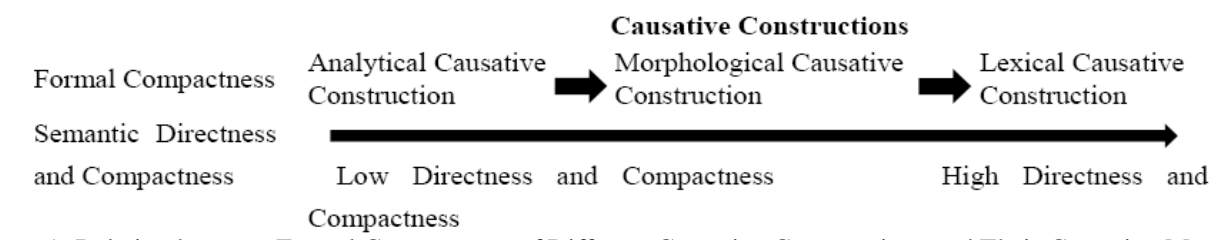

Figure 1: Relation between Formal Compactness of Different Causative Constructions and Their Causative Meanings

The syntax of CRC has been claimed to inherit from formal properties of all the three kinds of Causative Constructions. Similarly, the semantic properties, that is, the properties of causative meaning are also inherited from those Causative Constructions. More specifically, CRC is formally compact which means that it is also semantically compact and direct. Such a statement is verified by Ye \& Guo (2001) who have argued that causative meaning conveyed by CRC is direct since the temporal distance and conceptual distance between causing even and causing event is short. However, according to Zhan (2013), the conceptual or semantic distance between causing even and causing event cannot be too short. Otherwise, the acceptability of the CRC will decrease. For example, Zhan has conducted an extensive survey on (5) in large corpora and found that no instances are available. He argued that $k u$ 'weep' necessarily leads to yanjing shi 'eyes become watery', that is, the semantic distance between $k u$ 'weep' yanjing shi 'eyes become watery' is much too short, to the extent that $k u$-shi le yanjing does not convey enough information according to the Maxim of Quality in pragmatics advocated by Grice (1975). As a consequence, its acceptability is questionable.

$\begin{array}{rll}\text { (5) ???ku-shi } & \text { le } & \text { yanjing } \\ \text { Weep } & \text { PERF } & \text { eyes }\end{array}$

Lit.: wept and caused the eyes to become watery

Based on what has been discussed above, it is safe to draw the conclusion that semantics of CRC is motivated by Causative Constructions and specifically by Morphological Causative Construction since causative meaning expressed by $\mathrm{CRC}$ is direct and compact on the premise that it is not excessively direct.

\section{Diachronic Motivations For SyntaX And SEmantics of CRC}

Previous part has focused on the typological motivations for syntax and semantics of CRC, especially how syntactic and semantic properties of CRC can be explained through the typological relation between CRC and Causative Constructions. However, it does not expound where and how the syntax and causative meaning of CRC have arisen. 
This has to be dealt with from a diachronic perspective. Therefore, this part contributes to the diachronic motivations for syntax and semantics of CRC.

\section{A. Origins of $C R C$}

In ancient Chinese, there is no such construction as CRC in modern Chinese and causative meaning is expressed by causative use of non-causative verbs. The causativization of verbs can be achieved either through a change in tone or without any overt formal change. The former case can be exemplified by (4) whereby y̌n is causativized as yin by changing its tone while the latter can be instantiated by (6) whereby po 'break' is causativized without overt change.

(6) a. Liang bi po

Liang surely break

'Liang (an ancient state in Chinese history) will surely break down

$\begin{array}{llll}\text { b. Jiangjun } & \text { bi } & \text { po } & \text { Qin } \\ \text { General } & \text { surely } & \text { break } & \text { Qin }\end{array}$

General surely break Qin
'You (the General) will surely defeat Qin (an

(7) Peigong...sui ru po Qin

Peigong then get to break Qin

'Peigong (Liu Bang, the first emperor of Han Dynasty)... then got to Qin and defeated it.'

There are cases where the causativized verb is juxtaposed after another verb that denotes an event happening temporally before the event denoted by the causativized verb due to sharing objects or omission of pronouns such as $z h i$ (之), thus giving rise to the form [V V]. For example, $r u$ 'get to' and po 'break' in (7) are juxtaposed because they share the same Object "Qin". However, early [V V]s are Serial Verb Constructions instead of Resultative Constructions according to $\mathrm{Wu}$ (1999) who argued that the two juxtaposed verbs are syntactically loosely related since the separate form is much more frequent than the juxtaposed form. In addition, the semantic relation between the juxtaposed verbs is not so much cause-result relation as temporal sequential relation in that many verbs in the first slot of [V V] are not conceivable as causative verbs, for example $r u$ 'get to' in (7).

In a nutshell, CRC formally originates directly from the Serial Verb Construction [V V] and is semantically related to causative use of verbs in ancient Chinese. But how does the Serial Verb Construction [V V] evolve into CRC?

\section{B. Disyllabification, Semantic Shift and Constructionalization of CRC}

With evolution of Chinese language, there is a time period when both syntactic and semantic changes occurred to the Serial Verb Construction [V V] and the causative meaning expressed by causative uses of verbs shifted to [V V]. However, it is highly controversial as to when these changes happened exactly. In general, four time periods have been identified by previous diachronic studies, that is, Pre-Qin period (about 1500 BC-1100 BC), Han Dynasty (206 BC-220 AD), Six Dynasties period (386 AD-618 AD), and Tang Dynasty (618 AD-907 AD). We are not so much concerned with the specific time when changes occurred to the Serial Verb Construction [V V] as these changes per se.

Though scholars have not reached a consensus on the specific time period when the Serial Verb Construction [V V] is constructionalized to CRC, they do have on why these changes happened. Two major changes in ancient Chinese language have been observed in the history, i.e., declination of causativization of verbs and rising of disyllabification. It is claimed that ancient Chinese language witnessed a declination of causativization of verbs which is evidenced by emergence of [V Obj V] construction and combination of causative verbs such zhishi 'cause' with verbs previously causativized (Li, 1987; Wu, 1999; Jiang, 1999; Shi, 2011), as exemplified by (8a). In addition, rising of disyllabification in the history has also been witnessed, which not only happens to [V V] construction, but also other grammatical structures including nouns, adjectives, etc.

(8) zhishi tou po

Cause head break

Lit.: caused (his) head to be broken

'broke (his) head'

Declination of causativization of verbs and rising of disyllabification have exerted significant influence on Chinese grammar and brought about CRC. Specifically, with the declination of causativization of verbs, the second verb in Serial Verb Construction [V V] does not express causative meaning any more. Instead, it only expresses the result state. In this case, semantic neoanalysis happened to Serial Verb Construction [V V]. The result of this neoanalysis is semantic shift, that is, causative meaning previously expressed by causative use of the second verb is shifted to the whole structure. In this sense, [V V] acquired causative meaning through semantic shift. At the same time, due to the semantic neoanalysis and rising of disyllabification, the form of [V V] also changed. Previously the first $\mathrm{V}$ and the second $\mathrm{V}$ are in coordination which means they are symmetrical. However, after the semantic neoanalysis, they become syntactically asymmetrical though debates arise as to which one is head. In addition, [V V] changed into a single phonetic unit from previously a phonetic cluster of two phonetic units. With both semantic change and formal change in Serial Verb Construction [V V], CRC is constructionalized. The process of its constructionalization can be represented by Figure 2 . 


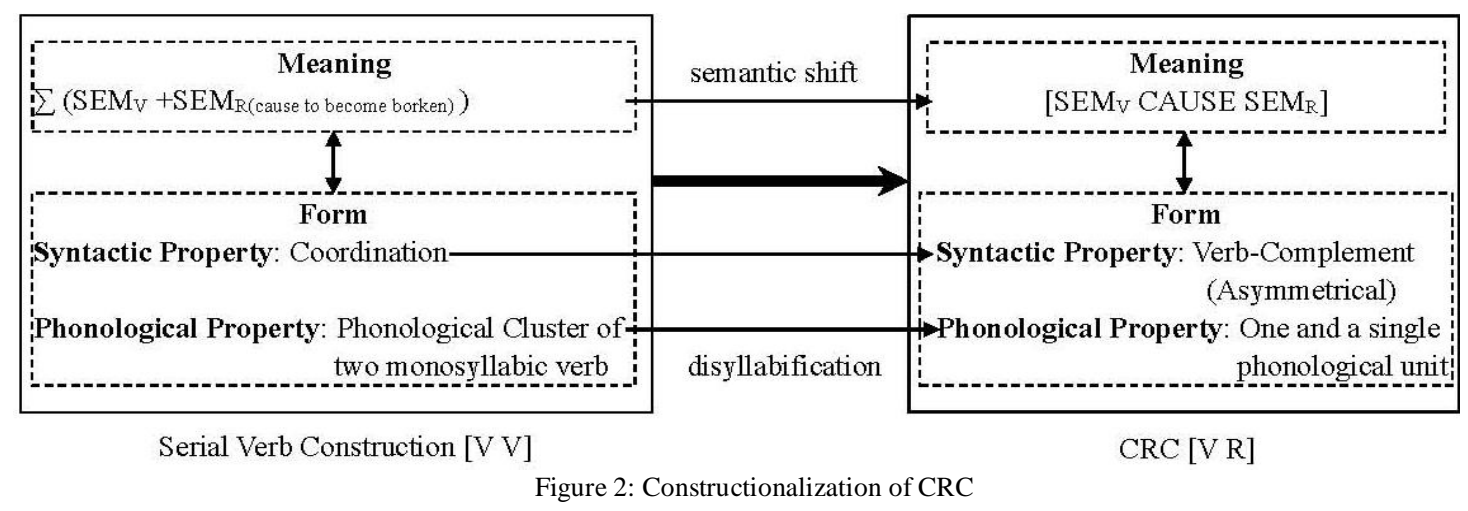

Through the diachronic investigation of how CRC has constructionalized, it becomes apparent that both syntax and semantics of CRC are diachronically motivated in that the syntax of CRC is historically inherited from Serial Verb Construction [V V] due to disyllabification and semantic neoanalysis while semantics of CRC is the result of semantic shift whereby causative meaning expressed by causative uses of verbs in the history of Chinese language is shifted to [V $\mathrm{V}]$ construction because of the declination of causativization of verbs.

\section{CONCLUSION}

This paper has been committed to the typological and diachronic motivations for syntax and semantics of CRC. It argues that CRC is a construction and Complex Predicate Construction in particular, and both its syntax and semantics cannot be fully motivated by its composing verbs. Taking into consideration the gestalt properties of its syntax and semantics, we reached the conclusions that: (i) syntax of CRC is typologically motivated by Causative Constructions in the sense that syntactic properties of CRC are inherited from both Analytical Causative Construction, Morphological Causative Construction, and Lexical Causative Construction, while semantic properties of CRC is typological motivated by Morphological Causative Construction in the sense that causative meaning expressed by CRC is direct and compact but not as direct as Lexical Causative Construction; (ii) syntax and semantics of CRC are diachronic motivated in the sense that syntax of CRC is inherited from Serial Verb Construction [V V] due to disyllabification and semantic neoanalysis while semantics of CRC is inherited from semantic shift through which causative meaning expressed by causative uses of verbs in the history of Chinese language shifted to [V V] construction because of the declination of causativization of verbs.

This paper offers a totally different perspective on motivations for syntax and semantics of CRC and provides a breakthrough for further research on syntax-semantics interface of CRC.

\section{ACKNOWLEDGEMENTS}

This paper is supported by the Fundamental Research Funds for the Central Universities (SWU1709443) and the Chongqing Social Science Planning Project (2014YBYY088).

\section{REFERENCES}

[1] Aikhenvald, A. Y. (2006). Serial verb constructions in typological perspective. In A. Y. Aikhenvald \& R. M. W. Dixon (eds.), Serial Verb Constructions: A Cross-linguistic Typology (pp.1-68). Oxford: Oxford University Press.

[2] Boas, H. C. (2003). A Constructional Approach to Resultatives. Stanford: CSLI Publications.

[3] Comrie, B. (1989). Language Universals and Linguistic Typology: Syntax and Morphology (2 ${ }^{\text {nd }}$ edition). Chicago: The University of Chicago Press.

[4] Dixon, R. M. W. (2000). A typology of causatives: Form, syntax and meaning. In R. M. W. Dixon \& A. Y. Aikhenvald (eds.), Changing Valency: Case Studies in Transitivity (pp.30-83). Cambridge: Cambridge University Press.

[5] Dixon, R. M. W. (2012). Basic Linguistic Theory (Volume 3): Further Grammatical Topics. Oxford: Oxford University Press.

[6] Fan, X. (2000). On Causative Constructions, Yufa Yanjiu He Tanshuo (Research (and Exploration) on Chinese Grammar), 10, 135-151.

[7] Grice, H. P. (1975) Logic and conversation. In P. Cole \& J. Morgan (eds.), Syntax and Semantics (vol.3): Speech Acts (pp.41-58). New York: Academic Press.

[8] Goldberg, A. E. (1995). Constructions: A Construction Grammar Approach to Argument Structure. Chicago: University of Chicago Press.

[9] Goldberg, A. E. (2006). Constructions at Work: The Nature of Generalization in Language. Oxford: Oxford University Press.

[10] Goldberg, A. E. (2013). Constructionist approaches. In T. Hoffmann \& G. Trousdale (eds.), The Oxford Handbook Construction Grammar (pp.15-31). Oxford: Oxford University Press.

[11] Guo, R. (1995). Valency structure and component integration of Chinese Resultative Construction. In Y. Shen \& D. Zheng (eds.), Studies on Valent Grammar in Modern Chinese (pp.168-191). Beijing: Peking University Press.

[12] Guo, R. (2002). Argument structure of Chinese Resultative Construction. In L.-J. Xu \& J.-M. Shao (eds.), Hanyu Yufa Yanjiu de Xin Tuozhan (New Trends in Chinese Grammar Studies) (1) (pp.169-186). Hangzhou: Zhejiang Education Publishing. 
[13] Guo, R., \& Ye, X.-Y. (2001). Typological perspective on Causative Constructions and Causative Constructions in Chinese. Paper from The First Kent Ridge International Roundtable Conference on Chinese Linguistics (KRIRCCL-I). Singapore: National University of Singapore.

[14] Haiman, J. (1985). Natural Syntax: Iconicity and Erosion. Cambridge: Cambridge University Press.

[15] Haspelmath, M. (2016). The serial verb construction: Comparative concept and cross-linguistic generalizations. Language and Linguistics, 17(3), 291-319.

[16] Her, O.-S. (2007). Argument-function mismatches in Mandarin resultatives: A lexical mapping account. Lingua, (1), 221-246.

[17] Hilpert, M. (2014). Construction Grammar and Its Application to English. Edinburgh: Edinburgh University Press.

[18] Huang, H.-C. (2008). Resultative Verb Compounds in Mandarin Chinese: A Constructional Approach. PhD Dissertation. Taiwan: National Tsing Hua University.

[19] Jiang, S.-Y. (1999). The time when Chinese Resultative Construction emerged. In X.-P. Yuan (ed.), Guoxue Yanjiu (Chinese Study) (6) (pp.327-348). Beijing: Peking University Press.

[20] Langacker, R. W. (1987). Foundations of Cognitive Grammar (I): Theoretical Prerequisites. Stanford: Stanford University Press.

[21] Langacker, R. W. (2005). Construction grammars: Cognitive, radical, and less so. In F. J. R. de Mendoza Ibáñez \& M. S. Peña Cervel (eds.), Cognitive Linguistics: Internal Dynamics and Interdisciplinary Interaction (pp.101-159). Berlin/New York: Mouton de Gruyter.

[22] Li, Y. (1990). On V-V compounds in Chinese, Natural Language \& Linguistic Theory, (2), 177-207.

[23] Li, Y. (1993). Structural head and aspectuality, Language, (3), 480-504.

[24] Li, Y. (1995). The thematic hierarchy and causativity, Natural Language \& Linguistic Theory, (2), 255-282.

[25] Li, Y. (1999). Cross-componential causativity, Natural Language \& Linguistic Theory, (3), 445-497.

[26] Li, P. (1987). Resultative Construction in Shi Shuo Xin Yu and Bai Yu Jing, Yuyanxue Luncong (Linguistic Treatise), 14, 129-157.

[27] Shen, J.-X. (2004). The Syntax and Semantics of "zhuilei" (chase-tired), Linguistic Sciences, (6), 3-15.

[28] Shi, C.-H. (2008). Syntax and Semantics of Chinese Resultative Construction. Beijing: Beijing Language and Culture University Press.

[29] Shi, D.-Xu. (1998). The complex nature of V-C construction. In Y. Gu (ed.), Studies in the Linguistic Sciences (pp.23-52). Hong Kong: Linguistic Society of Hong Kong.

[30] Shi, H.-M. (2011). Integration and Diachronic Change of Chinese Resultative Construction. Shanghai: Fudan University Press.

[31] Shibatani, M. (2002). Introduction: Some basic issues in the grammar of causation. In M. Shibatani (ed.), The Grammar of Causation and Interpersonal Manipulation (pp.1-22). Amsterdam/Philadelphia: John Benjamins Publishing Company.

[32] Song, W.-H. (2007). On the Syntax of Modern Chinese V-R Compounds: A Study Based on Conceptual Structures. Beijing: Peking University Press.

[33] Sybesma, R. (1999). The Mandarin VP. Dordrecht: Kluwer Academic Publishers.

[34] Wang, H.-Q. (1995). Research on valency of Chinese Resultative Construction. In Y. Shen \& D. Zheng (eds.), Studies on Valent Grammar in Modern Chinese (pp.144-167). Beijing: Peking University Press.

[35] Wang, Y. (2009). The embodied event structure approach to resultative constructions. Foreign Language Teaching and Research, (5), 345-350.

[36] Wang, Y. (2011). Researches on Construction Grammar. Shanghai: Shanghai Foreign Language Education Press.

[37] Wu, F.-X. (1999). On the origins of Modern Chinese Resultative Construction. In L.-J. Jiang \& J.-Y. Hou (eds.), Hanyu Xianzhuang Yu Lishi de Yanjiu (Research on Current Status and History of Chinese Language) (pp.317-345). Beijing: China Social Science Press.

[38] Xiong, X.-L., \& Wei, W. (2014a). A causative approach to reversal resultative constructions. Foreign Language Teaching and Research, (4), 497-507.

[39] Xiong, X.-L., \& Wei, W. (2014b). Towards a subject-oriented account of the "NP V LEI LE NP" resultative construction. Foreign Language Learning Theory and Practice, (2), 34-63.

[40] Xuan, Y. (2011). The resultative complement is an inner aspect: Telic Phrase Hypothesis of Chinese Verb-resultative Constructions. TCSOL Studies, (1), 67-78.

[41] Yuan, Y.-L. (2001). On the valence of verb-resultative constructions in Mandarin: Toward a top-down and bottom-up analysis. Studies of the Chinese Language, (5), 399-410.

[42] Zhao, Q. (2008a). Constructivity of Chinese from the Perspective of Chinese Resultative Construction. Fudan Forum on Foreign Languages and Literature, 2, 113-122.

[43] Zhao, Q. (2008b). Argument realization in Chinese and English Reflexive Resultatives. Shandong Foreign Language Teaching Journal, (6), 11-17.

[44] Zhao, Q. (2009a). A Comparative Study of English and Chinese resultative constructions. Foreign Language Teaching and Research, (4), 258-165.

[45] Zhao, Q. (2009b). Argument Realizations of English and Chinese Resultative Constructions. Doctoral Dissertation. Shanghai: Fudan University.

Canzhong Jiang was born in Xinyang, China in 1988. He received his Master's degree in linguistics from Southwest University, China in 2016.

He is currently a Ph.D. candidate in College of International Studies, Southwest University, Chongqing, China. His research interests include Cognitive Linguistics and Corpus Linguistics. 